\title{
Impact of Functional Endoscopic Sinus Surgery for Cases with Nasal Polypi on Pulmonary Function Tests
}

\author{
El-Sayed Attia Siam ${ }^{1}$ MD, Mohammad Amin Al-Morsy ${ }^{1}$ MD, Mahmoud Abou-Zaid Yahia Abbass ${ }^{1, *}$ \\ MB BCh
}

* Corresponding Author:

Mahmoud Abou-Zaid Yahia Abbass

drmahmoud268@yahoo.com

\section{Received for publication} January 15, 2020; accepted March 4, 2020; published on line March 4, 2020.

Copyright 2020 The Authors published by Al-Azhar

University, Faculty of

Medicine, Cairo, Egypt. All

rights reserved. This an openaccess article distributed under the legal terms, where it is permissible to download and share the work provided it is properly cited. The work cannot be changed in any way or used commercially.

doi:10.21608/aimj.2020.22403. 1078

${ }^{1}$ Otorhinolaryngology

Department Faculty of

Medicine, Al-Azhar University, Cairo Egypt.

\begin{abstract}
Background: The upper and lower airways form one contiguous and functionally related organ, and are frequently exposed to similar inflammatory stimuli. There is increasing interest in the possibility that disease processes in one part of the airway may be reflected or manifest in another, thereby providing opportunities for dual diagnosis and therapy.

Objective: To study the effect of removal of nasal polypi by functional endoscopic sinus surgery on pulmonary function tests.

Material and Methods: This prospective study was carried out at AlAzhar University hospitals (Al-Hussein and Bab El-Shaaria) in the period between December 2018 to December 2019 on 30 patients attended to outpatient clinics of ENT department to assess the effect of FESS on pulmonary functions of patients with a chronic rhinosinusitis with nasal polyposis without any other lung diseases.

Results: In the present study, we noted a significant improvement in mean FVC by $(0.25 \mathrm{~L}=7.6 \%)$ one month post operatively and by $(0.43$ $\mathrm{L}=13 \%$ ) three months post operatively. Also, there is a significant improvement in mean FEV1 by $(0.59 \mathrm{~L}=27.6 \%)$ one month post operatively and by $(0.92 \mathrm{~L}=43.2 \%)$ three months post operatively. Also, there is a significant improvement in mean FEV1/FVC \% ratio by $(19.3 \%)$ one month post operatively and by $(28.3 \%)$ three months post operatively.

Conclusions: This prospective randomized study showed that FESS have a positive effect on the pulmonary function of patients with chronic sinusitis with nasal polypi.
\end{abstract}

Keywords: Endoscopic sinus surgery; Nasal polypi; Pulmonary function tests.

\section{INTRODUCTION}

Both the upper and lower respiratory tracts are continually exposed to gases and airborne particles. The importance of host defence mechanisms is vital. Physical barriers, mucociliary clearance systems and cellular or humoral immune processes combine to protect the lung from damage. Where abnormalities of these mechanisms occur, the patient may first present to the otolaryngologist before serious bronchopulmonary involvement occurs. In the upper respiratory tract, cilia propel mucus, bacteria, and the particles trapped in mucus to the nasopharynx, where the mucus drops to the hypopharynx and is swallowed. In the lower respiratory tract, the cilia that line the trachea and bronchial tree similarly move the mucus blanket up the trachea and into the hypopharynx for swallowing. ${ }^{1}$

Patients who did not respond to pre-existing asthma treatment showed improvement after aggressive sinusitis treatment, therefore, the concept of "united airway disease" or "one linked airway disease" means that upper and lower airway diseases are different manifestations of one pathologic process. ${ }^{2}$
Authorship: All authors have a substantial contributions to the article.

Disclosure: The authors have no financial interest to declare in relation to the content of this article. The Article Processing Charge was paid for by the authors.

Chronic rhinosinusitis is an umbrella term for several disorders characterized by two symptoms or more lasting longer than 12 weeks. Sufferers may have pain or pressure over the face, a pus-filled discharge from the nose, blocked nose and hyposmia. The presence of a chronic inflammatory process can be demonstrated either radiologically or endoscopically. ${ }^{3}$

Chronic rhinosinusitis (CRS) can be divided into two types using the presence or absence of nasal polyps as a distinguishing feature. ${ }^{4}$

It has already been demonstrated by other researchers investigating nasal polyposis that applying steroids locally, or using mometasone furoate as an intranasal spray, can lead to both statistically and clinically 
significant reductions in polyp magnitude and airway obstruction, and helps counter hyposmia. Nonetheless, FESS remains a treatment of choice where nasal polyps have failed to respond to pharmacological measures, despite optimization. A recent finding is that, even where symptomatic/overt pulmonary disease is absent, sufferers from nasal polyposis had reduced pulmonary function. ${ }^{5}$

\section{PATIENTS AND METHODS}

\section{Patients:}

This study was conducted on 30 patients of different age groups of both sexes attending to outpatient clinics of ENT Department of Al-Azhar University hospitals (AL-Hussein and Bab El-Shaaria) in the period between December 2018 and December 2019 and they have chronic nasal problems in the form of nasal polypi. The decision was made to proceed with a surgical intervention.

A written consent was taken from all patients before the operation and the patients were provided with a patient information sheet which includes the details of the disease, the procedure, the risks of the procedure and possible outcomes.

\section{Inclusion criteria:}

In this study, we selected patients with chronic rhinosinusitis with bilateral nasal polypi, patients above 18 years and patients who are fit for anesthesia and surgical intervention.

\section{Exclusion criteria:}

In this study, we excluded patients with chronic chest diseases i.e. cystic fibrosis and COPD, patients changed their residence or occupation during the conduction of the study and patients who were taking bronchodilators.

\section{Methods :}

All patients were subjected to adequate medical, surgical and anesthetic history taking ,general examination ,chest examination ,ENT examination, including endoscopic sinus examination using $0^{\circ}$ \& $30^{\circ}$ lenses, CT nose and paranasal sinuses (coronal and axial views) and pulmonary function tests preoperative, one month and three months postoperative.

\section{Pulmonary function test using spirometer :}

The PFT values were considered to indicate a significant airway obstruction when FEV1/EVC $=0.7$ and FEV $1=80 \%$ of the predicted value for patient's age, height and weight. The apparatus used in this study (MICRO 5000 spirometer, medi-SOFT company for cardio-respiratory instruments, Sorinnes, Belgium).

\section{Procedure:}

Preparation of the patient (patient was asked about smoking, recent illness, medication use and weight, height and age were recorded).The purpose and method of the test was explained to the patient (correct posture with head slightly elevated). The test involved maximal rapid inspiration, followed by forced expiration of air through the mouthpiece sealed by mouth .

A clean, disposable mouthpiece was attached to the spirometer (a new one for each patient).After ensuring that the patient was comfortable, in particular that they were seated (in case they experience any faintness during the procedure). A clean nose clip was attached, a mouthpiece was placed in the mouth and patient was advised to close lips around this. The patient was asked to inhale completely and rapidly with a pause of no longer than 1 second at full inspiration and then to exhale maximally until no more air can be expelled while maintaining an upright posture.The patient was encouraged to keep blowing out. It was ensured that patient had exhaled for at least 6 seconds; the blow should continue until a volume plateau was reached. The procedure was repeated until three readings of which at least two of the FVC and FEV1 components were reproducible. Ideally, the expiratory volumetime graph should be smooth and free from irregularities.

\section{Operative techniques :}

The standard approach used in this study was functional endoscopic sinus surgery by $0^{\circ} \& 30^{\circ} 4$ $\mathrm{mm}$ rod endoscopes attached to camera connected to a video screen under general anesthesia. When the anatomy is visualized, the polyp tissue may be removed with polyp forceps, through cutting instruments or microdebrider.

An infundibulectomy was performed by incising the anterior attachment of the uncinate process. Then the ethmoidal bulla was opened and removed piecemeal. Behind the bulla, one enters a variable space, the lateral sinus, while superiorly, the skull base will be visible and the anterior ethmoidal artery can be identified

The patient was kept in the hospital overnight and discharged in the morning. Small temporary Merocel pack or antibiotic soaked gauze pack was placed in the surgical cavity. Packs were removed after the 48 $\mathrm{h}$ and patients were put on Antibiotics for 5-10 days depending on the severity of the disease along with alkaline nasal douche and an intranasal steroid spray. Patients were called for review 7-10 days following surgery and then as often as necessary. Patients were reassessed after a period of 1 and 3 months clinically and by PFT.

\section{Post-operative assessment of the patients was done through:}

Postoperative endoscopic sinus examination of the nose and paranasal sinuses.Pulmonary function tests: (1 month and 3 months after the operation) Specifically, postoperative forced expiratory volume at 1 second (FEV1), forced vital capacity (FVC) 
values and ratio between 2 values (FEV1/FVC) were calculated.

\section{Statistical analysis:}

Recorded data were analyzed using the statistical package for social sciences, version 20.0 (SPSS Inc., Chicago, Illinois, USA). Quantitative data were expressed as mean _+ standard deviation (SD). Qualitative data were expressed as frequency and percentage.

The following tests were done: A one way analysis of variance (ANOVA) when comparing between more than two means. Post Hoc test: Least Significant Difference (LSD) was used for multiple comparisons between different variables. The confidence interval was set to $95 \%$ and the margin of error accepted was set to $5 \%$. So, the p-value was considered significant as the following: Probability (P-value): $\mathrm{P}$-value $<0.05$ was considered significant. $\mathrm{P}$-value $<0.001$ was considered as highly significant. $\mathrm{P}$-value $>0.05$ was considered insignificant.

\section{RESULTS}

This study was conducted on 30 patients of different age groups of both sexes attending to outpatient clinics of ENT Department of Al-Azhar University hospitals (AL-Hussein and Bab El-Shaaria) in the period between December 2018 and December 2019 and they have chronic rhinosinusitis with bilateral nasal polypi.

\section{Demographic data}

\begin{tabular}{|l|c|c|c|c|}
\hline & Mean & SD & Minimum & Maximum \\
\hline Age & 45 & 11 & 32 & 61 \\
\hline BMI & 28 & 3 & 20 & 34 \\
\hline
\end{tabular}

Table 1: Demographic distribution of the study group according to age and gender.

\begin{tabular}{|c|c|c|}
\hline Sex & Count & \% \\
\hline Male & 18 & $60 \%$ \\
\hline Female & 12 & $40 \%$ \\
\hline
\end{tabular}

Table 2: Demographic distribution of the study group according to gender.

This study included 30 patients with age range 32-61 years, Mean \pm SD equlas $45 \pm 11$.

BMI ranged from 20 to 34 with Mean \pm SD of $28 \pm 3$. $18(60 \%)$ were males.

\section{Change of parameters after treatment:}

The study group results were put in comparison preoperatively one month and three months postoperatively regarding spirometric measurements:Forced vital capacity (FVC), Forced expiratory volume in the first second (FEV1) and FEV1/FVC \%

\begin{tabular}{|c|c|c|c|c|c|}
\hline & Mean & SD & $\begin{array}{l}\text { Mini } \\
\text { mum }\end{array}$ & $\begin{array}{l}\text { Maxi } \\
\text { mum }\end{array}$ & $\mathrm{p}$-value \\
\hline $\begin{array}{l}\text { Pre } \\
\text { operative } \\
\text { FVC }\end{array}$ & 3.27 & 0.43 & 2.70 & 4.00 & \multirow{3}{*}{$<0.01$} \\
\hline $\begin{array}{l}1 \quad \text { month } \\
\text { post- } \\
\text { operative } \\
\text { FVC }\end{array}$ & 3.52 & 0.44 & 3.00 & 4.26 & \\
\hline $\begin{array}{l}3 \text { months } \\
\text { post- } \\
\text { operative } \\
\text { FVC }\end{array}$ & 3.70 & 0.45 & 3.14 & 4.42 & \\
\hline $\begin{array}{l}\text { Pre- } \\
\text { operative } \\
\text { FEV1 }\end{array}$ & 2.13 & 0.29 & 1.76 & 2.60 & \multirow{3}{*}{$<0.01$} \\
\hline $\begin{array}{l}1 \text { month } \\
\text { post- } \\
\text { operative } \\
\text { FEV1 }\end{array}$ & 2.72 & 0.33 & 2.35 & 3.30 & \\
\hline $\begin{array}{l}3 \text { months } \\
\text { post- } \\
\text { operative } \\
\text { FEV1 }\end{array}$ & 3.05 & 0.38 & 2.60 & 3.60 & \\
\hline $\begin{array}{l}\text { Pre- } \\
\text { operative } \\
\text { FEV1/FV } \\
\text { C \% }\end{array}$ & $\begin{array}{c}64.8 \\
0\end{array}$ & 1.10 & $\begin{array}{c}63.0 \\
0\end{array}$ & $\begin{array}{c}67.3 \\
0\end{array}$ & \multirow{3}{*}{$<0.01$} \\
\hline $\begin{array}{l}1 \text { month } \\
\text { post- } \\
\text { operative } \\
\text { FEV1/FV } \\
\mathrm{C} \%\end{array}$ & $\begin{array}{c}77.2 \\
9\end{array}$ & 0.96 & $\begin{array}{c}75.8 \\
0\end{array}$ & $\begin{array}{c}78.6 \\
0\end{array}$ & \\
\hline $\begin{array}{l}3 \text { months } \\
\text { post- } \\
\text { operative } \\
\text { FEV1/FV } \\
\mathrm{C} \%\end{array}$ & $\begin{array}{c}83.0 \\
9\end{array}$ & 0.78 & $\begin{array}{c}81.8 \\
0\end{array}$ & $\begin{array}{c}84.2 \\
0\end{array}$ & \\
\hline
\end{tabular}

Table 3: The extent of difference over the period of fellow up through PFT in the study group.

As shown in the previous table, there is a significant improvement in mean FVC by $(0.25 \mathrm{~L}=7.6 \%)$ one month post operatively and by $(0.43 \mathrm{~L}=13 \%)$ three months post operatively.

Also, there is a significant improvement in mean FEV1 by $(0.59 \mathrm{~L}=27.6 \%)$ one month post operatively and by $(0.92 \mathrm{~L}=43.2 \%)$ three months post operatively.

Also, there is a significant improvement in mean FEV1/FVC \% ratio by $(19.3 \%)$ one month post operatively and by (28.3\%) three months post operatively .

The data from previous table are plotted in a line chart as in figures (1), (2) and (3). 


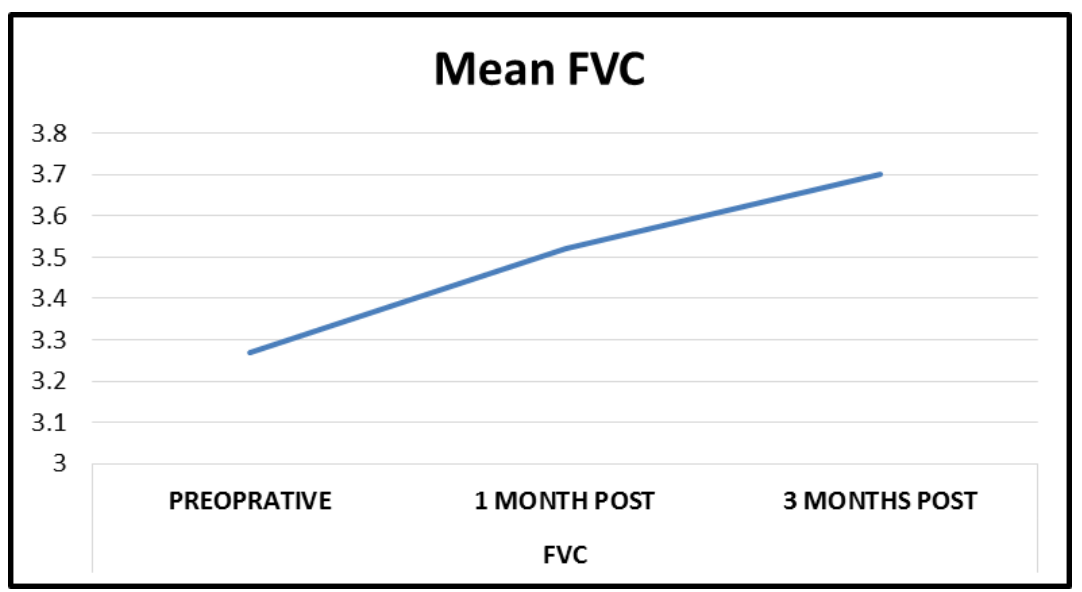

Fig. 1: Line shows the extent of difference over the period of fellow up through FVC in the study group.

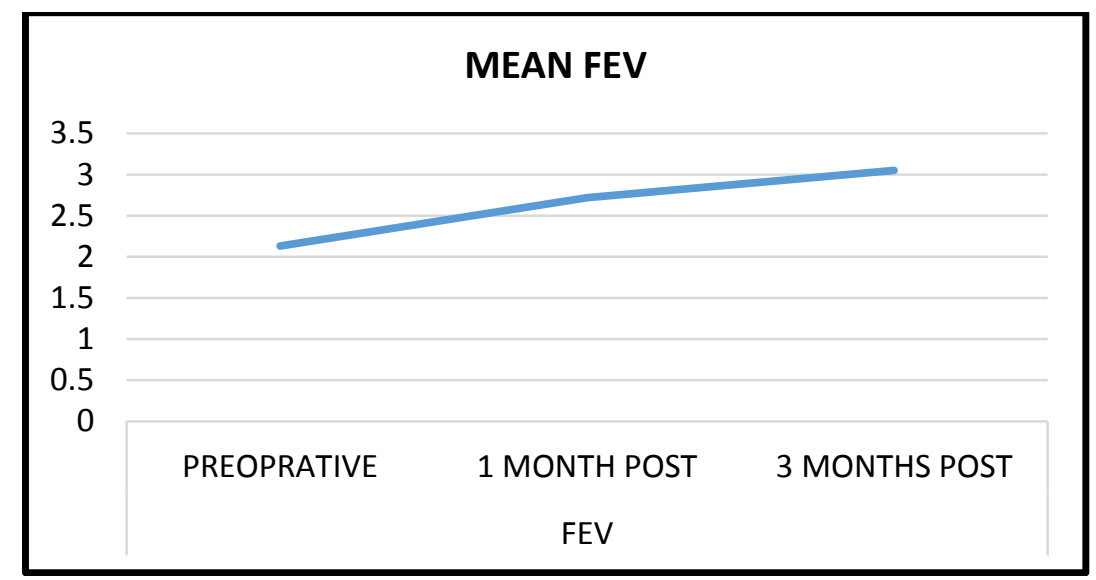

Fig. 2: Line shows the extent of difference over the period of fellow up through FVC in the study group.

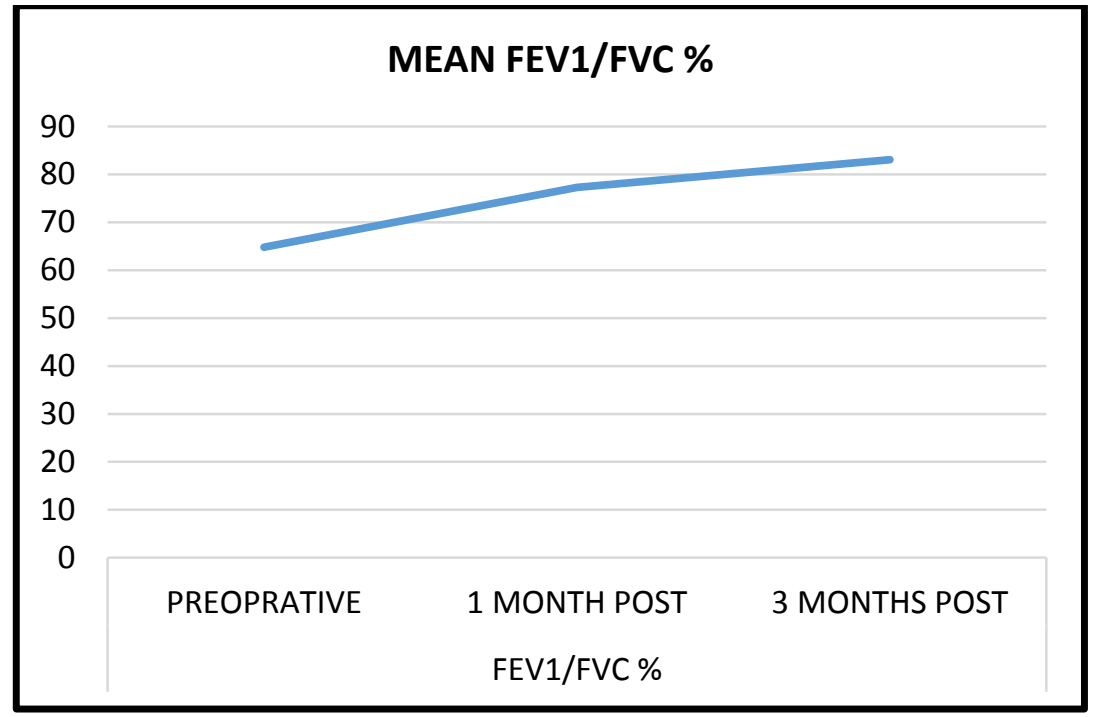

Fig. 3: Line shows the extent of difference over the period of fellow up through FEV1/ FVC \% in the study group. 


\section{DISCUSSION}

This study was done at Al-Azhar University hospitals (Al-Hussein and Bab El-Shaaria) on 30 patients attended to outpatient clinics of ENT department.

This prospective study was carried out to assess the effect of FESS on pulmonary functions of patients with a chronic rhinosinusitis with nasal polyposis without any lower airway diseases using the pulmonary function tests as indicator for effect before and after FESS.

The method we used for assessment was PFTs concentrating on (FVC \%, FEV1\% and FEV1/FVC $\%)$. PFT was assessed using Spirometer prior to surgery, 1 month and 3 months postoperative.

In a Normal case, FVC \% and FEV1\% should be greater than or equal to $80 \%$ of predicted, and the FEV1 to FVC ratio should be more than $70 \%$ of absolute percentage points of the predicted ratio.

The PFT values were considered to indicate significant airway obstruction when FEV1/FVC $<0.7$ and FEV $1<80 \%$ of the predicted value for a patient's age, height and weight ${ }^{5}$.

In the present study, by comparing the preoperative and postoperative statistical results of pulmonary function test of the study group we noted a significant improvement in mean FVC by $(0.25 \mathrm{~L}$ $=7.6 \%)$ one month post operatively and by $(0.43$ $\mathrm{L}=13 \%$ ) three months post operatively.

Also, there is a significant improvement in mean FEV1 by $(0.59 \mathrm{~L}=27.6 \%)$ one month post operatively and by $(0.92 \mathrm{~L}=43.2 \%)$ three months post operatively.

Also, there is a significant improvement in mean FEV1/FVC \% ratio by $(19.3 \%)$ one month post operatively and by $(28.3 \%)$ three months post operatively.

From the literature, it appears that Kariya et al. ${ }^{6}$ were the first to report the latent obstruction in low diameter airways associated with CRS. Their suggestion was that obstructive pulmonary alterations were present in CRS cases, even where they caused no symptoms and had not led to a diagnosis of obstructive airway disease.

Ciprandi et al. $^{7}$ concluded that $53.7 \%$ of chronic allergic rhinitis cases had associated decreases in measures of lung function.

Williamson et al. ${ }^{8}$ found the airways were impaired subclinically and FEV1 and FEF25-75 were both diminished, in CRSwNP.

Tanaka et al. ${ }^{9}$ revealed that an FEV1/FVC below $75 \%$ was present in $20 \%$ of cases of CRSwNP, but in such cases, asthma had not been diagnosed.

Lee et al. ${ }^{10}$ reached similar conclusions. Their finding was that if features of chronic sinusitis and nasal polyps were visible on CT, the airway would present obstacles to flow at a subclinical level, even if no underlying pulmonary pathology was present.
Zhang et al. ${ }^{11}$ investigated cases where FEF25-75 and FEV1 were diminished, and found that reduced pulmonary function had a correlation with chronic sinusitis and nasal polyps as shown by CT, in the absence of disease affecting the lower respiratory tract. They were able to show, too, that FEV1 and FEF25-75 were lowest in cases of CRSwNP, compared to CRS without nasal polyposis and cases lacking CRS altogether.

On contrary to the present study, the study of Ragab et al. ${ }^{12}$ showed no advantage of surgery over medical therapy. The I2-month pulmonary function values in the surgical group improved less than the pulmonary values in the medical group. This reached significance only for the polyposis subgroup. This was the only study with both a low risk of bias and the highest directness of evidence.

Also, Ragab et al. ${ }^{12}$, observed an increase in $\mathrm{FEV}_{\mathrm{I}}$ (\% of predicted) in both groups at 6 and 12 months. This improvement was sustained in the medical group. whereas in the surgical group the 12-month values had lost significance when compared to the 6month values. PFT $_{\mathrm{S}}$ improved in both groups. but this only reached significance in the total medical group and in the medical non-polypoid subgroup. In the polyposis subgroup, there was a significant difference in favour of the medical group.

In this study, there was an improvement in pulmonary function following endoscopic sinus surgery for patients of nasal polypi as evidenced by pre-and post-operative spirometric measures even in patients with no any lower airway diseases.

Even if the surgery was indicated for the upper airway disease. the improvement in lower airway function clearly signifies the concept of united airway and how functions of nose influences lung function as discussed earlier in the literature as compared to the pre-operative condition. Furthermore, more recent studies have demonstrated the efficacy of functional endoscopic sinus surgery on patients having CRSWNP in alleviating symptoms and enhancing QOL.

In the present study follow up was 1 month and 3 months after surgery. A significant improvement in the PFT value at 1 month postoperatively in study patients, reflecting the effect of sinonasal surgery on relieving the lower airway obstruction. These results also may be due to the post-operative usage of intranasal corticosteroid sprays that may lead to significant reductions in upper and lower airway responses to intense triggers. Usually the oedema phase takes approximately 30 days, and after three months the healing process is complete. So, improvement in PFT after 3months reflecting the positive effect of FESS on lung function.

Follow-up was rather short in all other studies except the study of Ragab et al. ${ }^{12}$ hence, it reports follow-up longer than 12 months and reports a negative effect of surgery on pulmonary function, but with a very small sample size.

In a different study population, Lamblin et al. ${ }^{13}$ report a significant decrease $\mathrm{FEV}_{1} / \mathrm{FVC}$ at 1 and 4 years follow-up, as well as a decrease of FEV1 
(\% pred) at 4 years follow-up in the surgical group. Pulmonary function remained stable in the medical group. In both studies the difference between groups was not statistically significant.

One of the merits of the present study that it was performed on patients having CRSWNP without any obstructive lower airway diseases (i.e bronchial asthma or COPD) and this in turn clarifies specificity and reliability.

Conclusively. According to this study patients with nasal polypi subjected to FESS showed postoperative maximum improvement in both spirometric measures and quality of life.

\section{CONCLUSION}

In conclusion, this prospective randomized study showed that FESS have a positive effect on the pulmonary function of patients with chronic sinusitis with nasal polypi, even in patients without any lower air way diseases and pulmonary function tests can be used as an objective analysis for the assessment of disease severity before and after FESS and can be used in long term follow up. Surgery earlier in the course of the disease gives a better outcome and could be beneficial to the patient.

\section{REFERENCES}

1. Ikeda K, Tanno N, Tamura G, et al. Endoscopic sinus surgery improves pulmonary function in patients with asthma associated with chronic sinusitis. Ann Otol -Rhinol Laryngol., 1999; 108(4):355-9.

2. Rachelefsky GS. National guidelines needed to manage rhinitis and prevent complications. Ann Allergy Asthma Immunol., 2003; 82(3):296-305.

3. Rosenfeld RM, Andes D, Bhattacharyya N, et al. Clinical practice guideline: adult sinusitis. Otolaryngol Head Neck Surg., 2007; 137(3):131.

4. Fokkens W, Lund V and Mullol J. European position paper on rhinosinusitis and nasal polyps. A summary for otorhinolaryngologists. Rhinology, 2007; 45:97-101.

5. Hankinson JL, Odencrantz JR and Fedan KB. Spirometric reference values from a sample of the general U.S. population. Am J Respir Crit Care Med., 1999; 159(1):179-87.

6. Kariya S, Okano M, Oto T, et al. Pulmonary function in patients with chronic rhinosinusitis and allergic rhinitis. J Laryngol Otol. 2014; $128: 255-62$.

7. Ciprandi G, Cirillo I, Vizzaccaro A, et al. Early bronchial airflow impairment in patients with persistent allergic rhinitis and bronchial hyperreactivity. Respir Med., 2005; 99 (12):1606-12.

8. Williamson PA, Vaidyanathan S, Clearie K, et al. Airway dysfunction in nasal polyposis: a spectrum of asthmatic disease? Clin Exp Allergy, 2011; 41(10):1379-85.
9. Tanaka S, Hirota T, Kamijo A, et al. Lung Functions of Japanese Patientswith Chronic Rhinosinusitis Who Underwent Endoscopic Sinus Surgery. Allergology International, 2014; 63:27-35.

10. Lee SY, Yoon SH, Song WJ, et al. Influence of chronic sinusitis and nasal polyp on the lower airway of subjects without lower airway diseases. Allergy Asthma Immunol Res., 2014; 6(4):310-5.

11. Zhang L, Zhang L, Zhang CH, et al. The Lung Function Impairment in Non-Atopic Patients With Chronic Rhinosinusitis and Its Correlation Analysis. Clin Exp Otorhinolaryngol., 2016; 9(4): 339-45.

12. Ragab SM, Lund VJ and Scadding G. Evaluation of the medical and surgical treatment of chronic rhinosinusitis: a prospective, randomised, controlled trial. Laryngoscope 2004;114: 923-30.

13. Lamblin C, Brichet A, Perez T, et al. Long-term Follow-up of Pulmonary Function in Patients with Nasal Polyposis. Am J Respir Crit Care Med., 2000;161:406-13. 